\title{
ENHANCING TEACHER COMPETENCIES WITH EMOTIONAL AND ETHICAL CAPACITY
}

\author{
Dr. Valentina Gulevska, University “St. Kliment Ohridski”, Faculty of Education, Bitola, Macedonia \\ E-mail:vgulevska@gmail.com \\ Dr. Tatjana Atanasoska, University “St. Kliment Ohridski”, Faculty of Education, Bitola, Macedonia \\ E-mail: tatjana_atanasoska@yahoo.com
}

Received: August, 11.2015.

Revised: August, 25.2015.

Accepted: September, 25.2015.

Studies and articles

UDK 371.132(497.7)

\begin{abstract}
A key element in contemporary qualifications frameworks is the specification of learning outcomes. The learning outcomes usually are described by the use of active verbs expressing knowledge, comprehension, application, analysis, synthesis, evaluation, etc. All this verbs describe a sphere of cognitive intelligence. But, rationality is only a part of the broad human potentials and powers. From there, affective components of learning can provide a valuable tool that helps teachers to enhance their competencies with emotional and ethical capacity. Those who have authority over others, such as the teachers, should be wary against the misuse of the power of their positions. For this reason, when we talk about the teachers' competency standards, we must take into account the feelings, reflections, interactions and ethical attitudes in education. This paper focuses on the important emotional and ethical aspects of the relationships that teachers have with their students.
\end{abstract}

Keywords: teachers, competencies, emotional and ethical capacity, education.

\section{INTRODUCTION}

Improving the quality of teacher education at the same time means improving the humanity as a whole. Good education simply presumes high quality of teachers. The goals of the teacher education need to be framed to cultivate not only knowing one's subject, learning the right techniques or methods, and being efficient, but also emotional and ethical competencies. Emotions are dynamic part of the human beings. Because of that all social organizations, including schools, are full of them. The impact of the emotions in the do-

Corresponding Author

Dr. Valentina Gulevska

University "St. Kliment Ohridski"

Faculty of Education, Bitola, Macedonia

E-mail: vgulevska@gmail.com main of education actually emphasizes the ethical dimensions of teaching and upbringing. Consequently, the most powerful energy in education is creating autonomous system of values among the learners, especially among the young people. From there, emotional intelligence facilitates understanding about the limitations of the cognitive intelligence.

Qualified teachers are not just professionals who demonstrate various forms of knowledge and ability to apply them in their work. Moreover, they are emotional and passionate beings who are connected with their students on many levels. Teachers fill their work and their classes, not only with knowledge and skills, but also with pleasure and joy, albeit they may have worry, hurt, and despair. In simpler words, the "cult of efficiency" that was imposed in the classrooms from the outside, by the external surveillance, appears as shadow upon the teaching which has a need of sensitive approach to the children's minds and hearts.

\section{RECENT CHANGES AND CHALLENGES IN MACEDONIAN EDUCATIONAL SYSTEM}

In the last ten years the educational system in Republic of Macedonia was undergoing radical changes in area of designing curricula, establishing of models for assessment, improving of the conditions for schooling and promoting of professional development for the teaching staff. The initiative for these reforms has emerged from combination of numerous and significant social and political events in the country.

Regarding the state's efforts for Euro integration, principally, we should point out the acceptance of the Bologna process in the high- 
er education and collaboration between educational institutions of all levels with intention to contribute for the exchange of opinions, experiences and information about the common issues of European education.

Simultaneously, the cultural and ethnical diversity of the civil society in Macedonia creates such circumstances in which educational institutions get a crucial role in promotion of ethical values and ideas like justice, equality, freedom, peace, compassion and charity, which are valued by many cultural traditions among young people. Also, the permanent growth of intercultural communication in the field of education motivates the teachers to look for a reasonable solution for the newly created situations in the organization of the school life.

Perhaps, more important is to know that after military conflict in Macedonia in 2001, academy has discussed whether the teaching of ethics in the frames of the educational curricula can really contribute students to get a larger picture for the social macrostructure and to strengthen awareness about existing biculturalism in Macedonian society on better way? The renewal of the spirit, after above mentioned turbulences, has consisted in the enrichment of people's thought with the belief in possible better future in the country. In particular, this has related to the youth (Gulevska, 2013).

Having in mind that school is still the most important factor which builds common goals and values among people, national policy makers met with a necessity of finding curricular solutions in Macedonian educational system in order to cultivate welfare and goodness in society. This approach couldn't bypass the faculties of education. Moreover, it could start only with university's support.

In Macedonia three are faculties of education. All three have proposed the subject Ethics as elective. At the Faculty of Education in Skopje the subject is offered in the first semester, for preschool teachers, and in the third semester, for elementary school teachers. Weekly fund of classes is $2+1$. At the Faculty of Education in Bitola the subject is offered in the first semester, for preschool teachers, and in the second semester, for the elementary school teachers. Weekly fund of classes is $3+2$. At the Faculty of Education in Shtip the subject is offered in the third semester, for preschool teachers, and in the seventh semester, for the elementary school teachers. Weekly fund of classes is $1+1+1$.

The Ethics curricula at the faculties of education have to contribute developing of the following knowledge, competences and skills among the students: 1) Knowledge of ethics in education; 2) Ability to apply theory in practice; 3) Self-awareness for professional duty; 4) Ability for collaboration and communication; 5) Intercultural competencies; 6) Capacity for empathy and social justice;

With this measure, already ten years teacher education in Macedonia tries to enhance teacher competencies with emotional and ethical capacity (Gulevska, 2013).

\section{OPEN QUESTIONS IN AREA OF THE COMPETENCY FRAMEWORK FOR TEACHERS}

According to the National Framework for Higher Education Qualifications for Republic of Macedonia (2011), the learning outcomes can be categorized and specified in various ways and may be expressed in a "qualification descriptors" for each of the cycles or levels. There are general descriptors of the qualifications in the National Framework, and they reflect the usual skills and accomplishments of the students and relate to the qualifications that indicate completion of specific study cycle.

Specific descriptors of qualifications that determine learning outcomes for individual study program from the corresponding cycle are prepared by the higher education institution.

Data on skills and accomplishments acquired by the students, as well as the use of qualification are disclosed in the Diploma supplement. Although the NF-HEQ has the flexibility to accommodate diversity and innovation, and to accommodate new qualifications, generally, the qualifications that signify a successful completion of the first cycle of study $(180$ - 240 ECTS) are awarded to person who meets the following descriptors of qualifications:

\section{Knowledge and understanding}

- Have demonstrated knowledge and understanding founded upon prior education and training within the main field of study, including knowledge about the rang of theoretical, practical, conceptual, comparative and critical perspectives in the field within appropriate methodology;

- Understanding in a particular area and familiarity with current research issues and new sources of knowledge;

- Have demonstrated knowledge and 
understanding of various theories and methodologies;

Applying knowledge and understanding

- Can apply their knowledge and understanding in a manner that indicates a professional approach to work or vocation;

- Have demonstrated competences for identifying, analyzing and solving problems;

- Be able to devise and sustain arguments within their field of study;

Making judgment

- Ability to gather, analyze, evaluate, and present information, ideas, concepts from relevant data;

- Exercise appropriate judgment, taking into account relevant personal, social, scientific or ethical aspects;

- Ability to evaluate theoretical and practical issues, to explain the reasons and choose an appropriate solution;

\section{Communication skills}

- Can communicate and discuss information, ideas, problems and solutions on the context where criteria for decisions and the scope of the task may be well defined to both specialist and non-specialist audiences;

- Take shared responsibility for collective results;

- Ability for independent participation into specific, scientific and interdisciplinary discussions, with a professional approach;

\section{Learning skills}

- Take initiative to identify and address learning needs for further knowledge and ongoing learning, with a high degree of autonomy.

Nowadays, in order to accomplish this mission, teachers have devoted considerable energy to define the field of their professional competencies.

On the basis of NF-HEQ in Macedonia has been developed Catalogue of Key Competencies for Teachers (which will be published soon) through analysis of national and international teacher competencies and consultation with members of the teaching profession.

The Catalogue contains three main parts:

- Professional values;

- Professional knowledge and skills; and

- Indicators for professional practice.

In the text is emphasized that this three parts are connected mutually. Item in the first chapter is said that the professional values and beliefs of the teachers are important factor which influences the teachers' decisions. From this factor depends how the teachers will plan the teaching process, how will conduct oneself towards the students, colleagues and broader community. The chapter continues with statement that professional attitudes and values can be acquired and can be changed in the time through professional improving and practice. Next, the text enumerates six key professional values for the teachers:

- Believes that each student can learn and develop himself;

- Understands teaching profession as process of lifelong learning;

- Dedicated is to the profession and contributes for its affirmation in the broader community;

- Develops partnership relations with all factors in the teaching process;

- Promotes equality, inclusion and social justice;

- Accepts and represents the principles upon which is based educational system in Macedonia.

In the other two chapters presented are identification of key competencies and development of indicators by which the competencies can be evaluated. Emphasized is that key competencies, described in the Catalogue, refer to the knowledge, understandings, abilities and skills which should have each teacher in order to realize his work good enough.

In continuation, the text of the Catalogue analyses only the key competencies which are grouped in certain domains, for example as knowledge of subjects, planning and realizing of teaching, creating climate for learning, collaboration with the parents and local community, professional development end so on. Finally, in the end of the Catalogue, just is mentioned shortly that competencies are connected with professional values. It seems that actually only two last chapters in the Catalogue are really connected. Obviously, between the first and other two chapters exists a detachment.

\section{STRIVING FOR REVELATION OF THE LOVE'S WONDER IN TEACHING}

In general, this paper is not an attempt to incite consideration for development of new catalogue, but rather a theorisation to integrate particular philosophy in the available model of teachers' competencies framework. It has found that there are substantial reasons for defining more clearly the competencies that teachers should deploy in the social contexts' complexity of contemporary world. 
What society expects from teachers? The investigations in this field showed that parents usually want public schooling to support children's ability to become lifelong learners who are able to love, work, and act as responsible members of the community (Cohen, 2006). Are these values substantively integrated into our schools or into training we give teachers?

According to opinion of some scholars, competence is defined as complex combination of knowledge, skills, understanding, values, attitudes and desire, which leads to effective embodied human action in the world, in a particular domain (Crick, 2008). In this sense, the teachers should demonstrate his qualities on different ways: through the structuring of the lectures and its evaluation, through the choice of the curriculum and pedagogy, through the cultivating of intellectual and moral virtues, finally, through his own behavior in the classroom and workplace. In other words, the teacher's skills and competencies should be conceptual, empirical, and interrelated with sensitivity for professionalism and school culture (Campbell, 2003). Therefore, researching of the each of this elements, singly contributes for the creation of clear perception about what is quality teaching staff. In this context, teachers are seen as key players in values education. Also, it's clearly that teachers' emotions, endeavors, desire and hope can motivate, help or inspire their students.

On the contrary, contemporary tendencies in developing competency framework for teachers make unwarranted marginalization of the discourse for emotionality and ethical capability in the teaching. Admittedly, the identification of behaviors which manifest certain values isn't simple and discernible, but rethinking education must take into account the love which focuses on the growth and development of children.

Key indicators which are treated as valid for these competencies usually anticipate applying the Code of Ethics and identifying statutory grounds and procedures for disciplinary action. In our opinion, knowledge of the ethics' codes for professional conduct in education isn't overriding in development of teachers' ethical capacity. More important is making efforts to protect students from conditions harmful to learning, devotion to truth, pursuit of reasonable standards that will guarantee freedom to learn and will provide equal opportunity for all.

A good teacher should maintain a climate in the classroom that promotes cultivating positive emotions and bridging the gap between children regarding their background, particular weaknesses or disabilities and their different talents (Toomey et al., 2010). Of course, teachers cannot make always children understand or love each other, but they may create conditions making it increasingly possible, because in the schools students have not only to learn, they also have to soar.

It is wrong to regard some occupations as more important as such than others, but the teachers' profession requires more reconsidering and more introspectiveness than other professions. In this sense, the teachers should possess capacity for autonomy, i.e. ability for independent making of decisions and accountability for them (Strain and Robinson, 2005). Also, they should acquire stronger self-monitoring skills. Exclusively is important, the future teachers to acquire knowledge about how to act, not only as a specialists in the educational field, but as citizens of a given society.

According to Aristotle, the human being is destined to live in community, and therefore his nature has a moral character. From there, understanding of the competencies as ,,skills free from theory and philosophy" is criticized with a good reason, owing to underestimating of significance of the beliefs, the attitudes and the values as important aspects of the teacher's profession (Pantić, 2008). The key document for this issue is Common European Principles for Teacher Competences and Qualifications, in which, besides knowledge, contents of the curricula, pedagogical innovations and researching, emphasized is the cultural and social dimension of the teaching. In the frames of the expertness included are principles which have ethical dimension. For example, such principles are: ability for critical thinking, development of an own system of values, devotion upon profession and work with children, ability to make and maintain positive interpersonal communication with the students, colleagues and parents, ability for good discipline in practice, ability to be a moral model for the children and so on. Anyway, deeper analysis of ethical nature of teaching and recognition of the emotions' immense impact in this process there are missed.

The "soft" aspects of pedagogy emphasize interrelationship between socialemotional capacity and ethical dispositions in human life. In order to better understand role of emotional intelligence some educational researchers try to find a stimulus which will provoke emotional reaction. According to them, emotional logic is different from intellectual logic. For its functioning is not essential di- 
rect connection between the reason and the consequence because emotional logic refers to the sequences of facts which are inside of the human needs and pleasures (Pharand, 2013). At the same time, emotions bring immense energy in actions. This energy isn't danger by itself if is properly directed. Moreover it is something valuable as much as intellect. In teaching, emotional energy plays a crucial role. It makes influence upon teaching style and students' successes or failures. Also, this energy creates such human closeness which draws down "professional walls", and opens a new horizons in education.

The empiricists claim that human knowledge comes from impressions made over us by physical objects. Consequently, the deepest knowledge will come from the objects which impress our mind particularly. Such marvelous object which impress children's eyes and mind is teacher in his whole nature and emergence, with his body and soul, with his mind and heart, with his intellect and feelings.

So, we can conclude that the teacher is main source of knowledge in the schooling. This epistemological perspective of the teacher's position, according to Zembylas is grounded in post-structuralist views (Zembylas, 2011). The issues of culture, power, and ideology, developed by Foucault in his later works, demonstrate how the teacher can cultivate his ethical "self" through a range of reflective practices that are deeply connected to his emotions. The teacher should define certain mode of being that will serve as his moral goal, and this requires him to act upon himself, to monitor, test, improve and transform himself. In this point appears in sight the big picture of teacher's power and accountability. Knowledge is always an ethical practice. It is principally power for government of the self (Ball, 2013).

Also, exclusively is important to include into teachers' competencies knowledge and awareness about the one's own identity. Actually, this kind of knowledge resurrects the old philosophic questions: What it means to be a happy and good human being? What it means to act and live according to own ideals?

According to Clarke (2010), identity is an indispensable resource for teachers in thinking about what they believe, what they stand for and what they do: in short how they define who they are. Also, emphasized is that the pursuit of identity is entwined with tension and paradox, stemming from its dependence on many different relations. There are ever-frustrated efforts to capture and define the plenitude of life that always exceeds these attempts and therefore the teacher is crucified between his thoughts and emotions, between actuality and desire. This medial state is state of uninterrupted desiring, irresistible striding in unknown, because love makes us, as human beings, vulnerable and that vulnerability invites loss and grief. These are the necessary shadows, the natural corollary to a loving engagement. Learning how to deal with these losses is a part of life and ought to be part of learning if we are learning to be creative, human, and wise (Liston and Garrison, 2004).

Finally, in contrast to professional "cold blood" we encourage emotional warmth in teaching. Teachers may develop such kind of emotional and ethical competencies which will refer to all educational practices (Lafortune et al., 2008). For example:

- Analyzing one's own emotions and how its affect students;

- Identifying own values;

- Recognizing own feelings, interests and strengths;

- Evaluating motivation of students;

- Preventing interpersonal conflicts;

- Making decisions based on the own ethical beliefs;

- Celebrating students success;

- Providing students opportunities talk about themselves, etc.

This list can be very long. It is transversal perspective of the embracing love in teaching as common line in all teachers competencies.

\section{CONCLUSION}

Having in mind all above mentioned, we have to acknowledge that is certainly difficult to find quantifiable measuring of the teachers' emotional and ethical capacities according to standards, dictated by predefined indicators of successful performance and effectiveness. Among other things, it is additionally complicated by the outlook of specific cultures, regions and societies.

With regard to this, should be noted that even in the latest educational researches highlighted are those technical dimensions of teaching which emphasize procedure, clarity, transparency, and application to rules. Also, asserted is that learning from experience may be valuated highly in this context, too (Ellis and Orchard, 2014).

But, in spite of all, contemporary educational policy makers very often face to question how to harness in the field of teaching 
those human powers and capabilities which don't function always according to canons of rationality. For example, isn't easy to explain why ethical efforts of the human beings, on its merits, doesn't always promise happiness or why the pure love for mankind is sometimes more esteemed than money, name or fame?

Following from this, some experts criticized subjecting of the teachers competencies to tests concerning their immediate use and applicability as underestimating the aims and values underlying teaching (Cowen, 2009). In our "rational", "efficient" and "technical" society docility of the formal control and regulations becomes necessity. But, power of knowledge shouldn't be used in any kind of pressure (even of moral pressure), but in revitalization and cultivating human liberty conceived as freedom from having beliefs.

As we have seen, attempts for changes in this education area are numerous, but the reforms must go further and more boldly.

\section{Conflict of interests}

Authors declare no conflict of interest.
Curricula. In Teaching and Learning: the Quality of the Educational Process, International Conference Proceedings. Užice: Teacher-Training Faculty, 111-120.

Lafortune, L., \& Ouellet, S. (Eds.). (2008). Réfléchir pour évaluer des compétences professionnelles à l'enseignement: deux regards, l'un québécois et l'autre suisse (Vol. 23). PUQ.

Liston, D. P., \& Garrison, J. W. (2004). Teaching, learning, and loving: Reclaiming passion in educational practice. Psychology Press.

Pantić, N. (2008). Tuning teacher education in the Western Balkans. Belgrade: Centre for Education Policy.

Pharand, J. (2013). En éducation, quand les émotions s' en mêlent!: enseignement, apprentissage et accompagnement. Presses de l'Université du Québec.

Strain, J., \& Robinson, S. (Eds.). (2005). The Teaching and Practice of Professional Ethics. Troubador Publishing Ltd.

Toomey, R., \& Clement, N. (Eds.). (2010). International research handbook on values education and student wellbeing (pp. 23-24). Dordrecht: Springer.

Zembylas, M. (2011). Investigating the emotional geographies of exclusion at a multicultural school. Emotion, Space and Society, 4(3), 151-159.

\section{REFERENCES}

Bahtovska, E., Janevska, G., Neshkovska, R. (2011). National Framework for Higher Education Qualifications for Republic of Macedonia. University „St. Kliment Ohridski“. Bitola.

Ball, S. J. (Ed.). (2013). Foucault and education: Disciplines and knowledge. Routledge.

Caena, F. (2011). Literature review-Teachers ${ }^{\text {ce }}$ core competences: requirements and development. European Commission Thematic Working Group 'Professional Development of Teachers'(Brussels, European Commission). Retrieved from http://ec.europa.eu/education/ policy/strategic-framework/doc/teacher-competences en.pdf.

Campbell, E. (2003). The ethical teacher. McGraw-Hill Education (UK).

Clarke, M. (2010). Doing identity work in teacher education: The case of a UAE teacher. World yearbook of education, 145-162.

Cohen, J. (2006). Social, emotional, ethical, and academic education: Creating a climate for learning, participation in democracy, and well-being. Harvard educational Review, 76(2), 201-237.

Cowen, T. (2009). Creative destruction: How globalization is changing the world's cultures. Princeton University Press.

Crick, R. D. (2008). Key Competencies for Education in a European Context: narratives of accountability or care. European Educational Research Journal,7(3), 311-318.

Ellis, V., \& Orchard, J. (Eds.). (2014). Learning Teaching from Experience: Multiple Perspectives and International Contexts. A\&C Black.

Gulevska, V. (2013). Ethics in Macedonian Educational 